\title{
Is it possible folic acid reduce anorectal malformations ethylenethiourea induced in rats? ${ }^{1}$
}

\author{
Danilo José Fiorindo Faria', Manuel de Jesus Simões", José Luiz Martins ${ }^{\text {III }}$
}

DOI: http://dx.doi.org/10.1590/S0102-865020150080000001

IFellow Master degree, Postgraduate Program in Interdisciplinary Surgical Science, Universidade Federal de São Paulo (UNIFESP), Brazil. Conception, design, and scientific content of the study; technical procedures, analysis and interpretation of data, manuscript preparation.

IIPhD, Associate Professor, Histology and Structural Biology Division, Department of Morphology, UNIFESP, Sao Paulo-SP, Brazil. Histophatological examinations.

IIIPhD, Full Professor, Department of Pediatric Surgery, UNIFESP, Sao Paulo-SP, Brazil. Conception and design of the study, critical revision, final approval of the manuscript.

\begin{abstract}
PURPOSE: To investigate the effect of folic acid (FA) in an experimental model of anorectal malformations (ARMs) ethylenethiourea (ETU) induced.

METHODS: Eight female Wistar rats were divided randomly in two groups. Group A - ETU; Group B - FA+ETU; Dams from group $\mathrm{B}$ received daily, since two weeks before pregnancy to the end of pregnancy, FA $(50 \mathrm{mg} / \mathrm{kg})$ by gavage. Dams from groups A and B, received $1 \%$ ETU $(125 \mathrm{mk} / \mathrm{kg})$ by gavage on gestational day (GD) 11 . Their fetuses were harvested by cesarean section on GD21 and were examined looking for ARMs. The thickness of anal stratified squamous epithelium (ASSE) and intestinal epithelium (IE) were analyzed. $\mathrm{p}<0.05^{*}$.

RESULTS: One hundred and one embryos were harvested. The number of embryos; number of ARMs; mean statistical \% ( \pm SD) were determined to be, respectively: ETU $-49[30 ; 65 \%( \pm 24 \%)]$ versus FA+ETU $-52[1 ; 02 \%( \pm 3 \%)](p=0.025)$. AMRs were significantly lower in FA+ETU group than in ETU group ( $p=0.025)$. The thickness $(\mu \mathrm{m})$ of ASSE $( \pm \mathrm{SD})$ and IE $( \pm$ SD) were measured, respectively: ETU $-[27.75( \pm 0.56)$ and $18.88( \pm 0.93)]$ versus FA+ETU $-[28.88( \pm 0.61)$ and $21.11( \pm 0.16)](p=0.001)$. The thickness of IE was significantly enlarged when FA was given $(\mathrm{p}=0.001)$.
\end{abstract}

CONCLUSION: Folic acid reduces the number and enlarged the IE of ARMs ETU-induced.

Key words: Anal Canal. Anus, Imperforate. Ethylenethiourea. Folic Acid. Rats. 


\section{Introduction}

Anorectal malformations (ARMs) represent a broad spectrum of congenital anomalies, including anorectal and urogenital sinus defects. The incidence rate is approximately 1 per 5000 live births ${ }^{1}$, occurring most frequently in males. Usually, AMRs affect the terminal hindgut, anus, pelvic floor muscle (PMF) and striated muscle complex (SMC), innervations of PMF and SMC, and urogenital and spinal defects. Posterior sagittal anorectoplasty (PSARP) has been proposed as gold standard surgery ${ }^{2}$. Despite various advances in this technique, poor postoperative anorectal functions still remain as major problem. Fecal incontinence, constipation and voiding dysfunction are observed.

ARMs pathogenesis and morphogenesis remains unclear. Different teratogenic drugs have been used to mimic ARMs in rats. One of the most published is ethylenethiourea (ETU) ${ }^{3}$.

Good evidence from randomized trials suggests folic acid (FA) reduces the risk for neural tube defects (NTD). Maternal consumption of folic acid before pregnancy and during early pregnancy is associated with a reduced risk for some other birth defects. The rate of ARMs was greater among mothers who did not take folic acid than mothers who took folic acid before pregnancy. Daily maternal consumption of $400 \mu \mathrm{g}$ of folic acid could reduce the risk for $\mathrm{AMRs}^{4}$.

The aim of this study was to investigate the protect effect of FA in an experimental model of ARMs ETU-induced.

\section{Methods}

Ethical approval was obtained from the Research Ethics Committees of the Universidade Federal de São Paulo prior to the study (Protocol n 1859/11).

Eight female mature Wistar-EPM rats were provided from the Central Biotery of the Federal University of São Paulo. Rats were divided randomly in two groups. Group A - ETU and Group B - FA+ETU.

Dams from group B received daily, since two weeks before pregnancy to the end of pregnancy, FA $(50 \mathrm{mg} / \mathrm{kg})$ by gavage.

Rats received commercial feed and water ad libitum, under constant environmental conditions of temperature and humidity, with 12-hour day and night cycles using artificial light, controlled automatically. After one night of mating, dams who presented a vaginal smear with the presence of spermatozoids were considered to be potentially fertilized. This was considered to be day zero (GD0) of gestation. Dams were kept in individual cages.
On gestational day (GD) 11, dams from both groups received $1 \%$ ETU $(125 \mathrm{mk} / \mathrm{kg})$ by gavage.

On GD21, dams were anesthetized with 2\% Xylazine (60 $\mathrm{mg} / \mathrm{kg}$ ) and $10 \%$ Ketamine $(10 \mathrm{mg} / \mathrm{kg})$ by intramuscular injection. Fetuses were harvested by cesarean section and were initially examined externally looking for AMRs. Dams were sacrificed by cervical dislocation. Following this, fetuses were underwent exploratory laparotomy to characterize the type of ARMs. Terminal intestine was removed to histological analysis.

Fragments of terminal intestine were fixed in $10 \%$ buffered formaldehyde, dehydrated and embedded in paraffin, stained with hematoxylin and eosin, and examined microscopically by a blind examination. The thickness of anal stratified squamous epithelium (ASSE) and intestinal epithelium (IE) were analyzed.

Non-parametric tests were used when samples tested against normal distribution. Kruskal-Wallis test was used to compare different groups and Mann-Whitney test when comparing two groups. Parametric tests were used in the histological analysis. Thickness was compared using two way Analysis of Variance (ANOVA) and post hoc Turkey test. Significant differences were considered when $\mathrm{p}<0.05$.

\section{Results}

One hundred one fetuses were harvested. There were 49 fetuses from group A (ETU) and 52 fetuses from group B $(\mathrm{FA}+\mathrm{ETU})$.

In the ETU group, the mean weight of dams on GD0 and GD21 was, respectively $229.50 \mathrm{~g}$ and $324.25 \mathrm{~g}$. In the FA+ETU group, the mean weight of dams on GD0 and GD21 was, respectively $212.50 \mathrm{~g}$ and $298.75 \mathrm{~g}(\mathrm{p}>0.05)$. In the ETU group, the mean weight of fetuses \pm standard deviation (SD) was $2.20 \pm$ 0.62 . In the FA+ETU group, the mean weight of fetuses $\pm \mathrm{SD}$ was $5.89 \pm 0.60(\mathrm{p}=0.025)$.

Statistically significant differences were observed comparing ARMs in two groups (Table 1). Folic Acid reduces the number of ARMs ETU-induced $(p=0.025)$.

TABLE 1 - Presence of ARMs.

\begin{tabular}{ccccc}
\hline Group & Fetus & ARM & $\begin{array}{c}\text { Statistical } \\
\text { Mean (\%) }\end{array}$ & SD (\%) \\
\hline ETU & 49 & 30 & $65 \%$ & $24 \%$ \\
AF + ETU & 52 & 1 & $2 \%$ & $3 \%$ \\
\hline
\end{tabular}


Others anomalies were observed. Short or absence tail was observed in all ARMs. Limb defects, coexisting or not with ARMs, facial defects, spinal defects were observed in both groups (Figures 1 and 2). There was no significant difference $(\mathrm{p}>0.05)$.

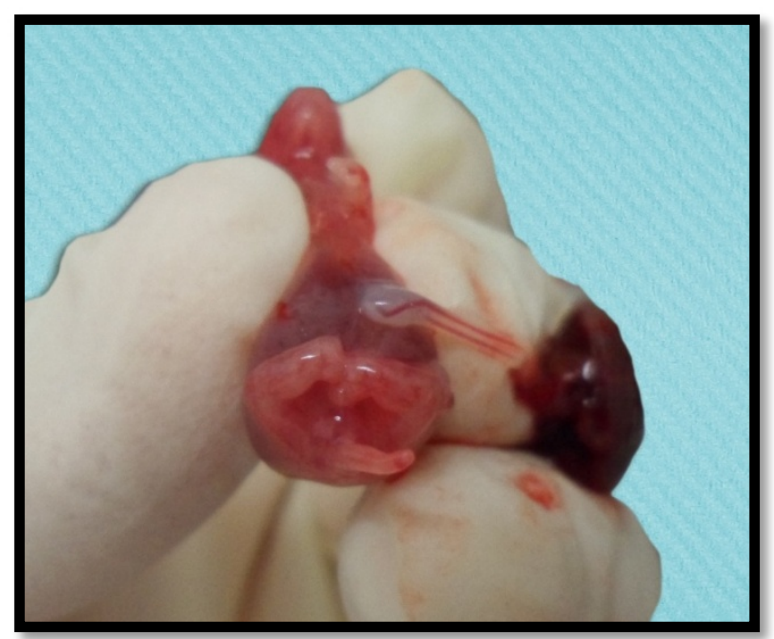

FIGURE 1 - ARM, short tail and limb defects - ETU group.

TABLE 2 - Thicknes of ASSE and IE.

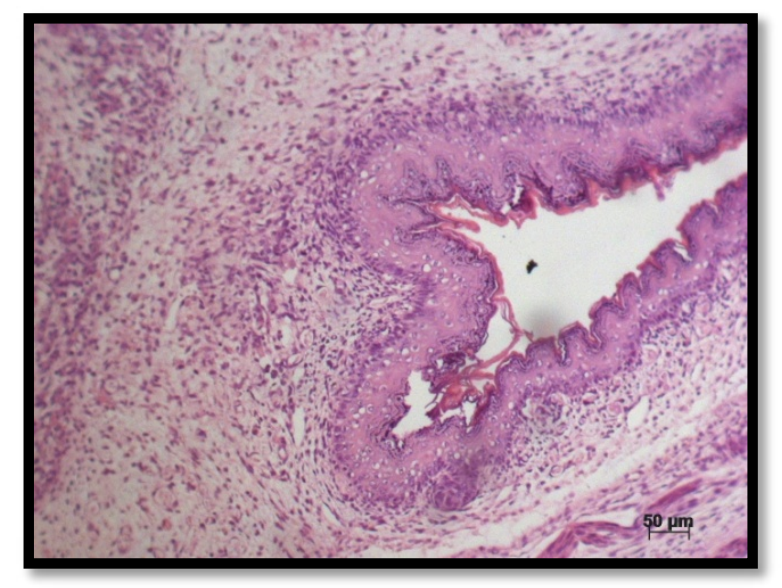

FIGURE 3 - Thickness of ASSE - ARM - ETU-group (x20).
The thickness of anal stratified squamous epithelium (ASSE) and intestinal epithelium (IE) were analyzed (Table 2, Figures 3 and 4). Statistic significant differences were not observed on thickness of ASSE ( $>>0.05$ ). However, the thickness of IE was significantly enlarged when FA was given $(\mathrm{p}=0.001)$.

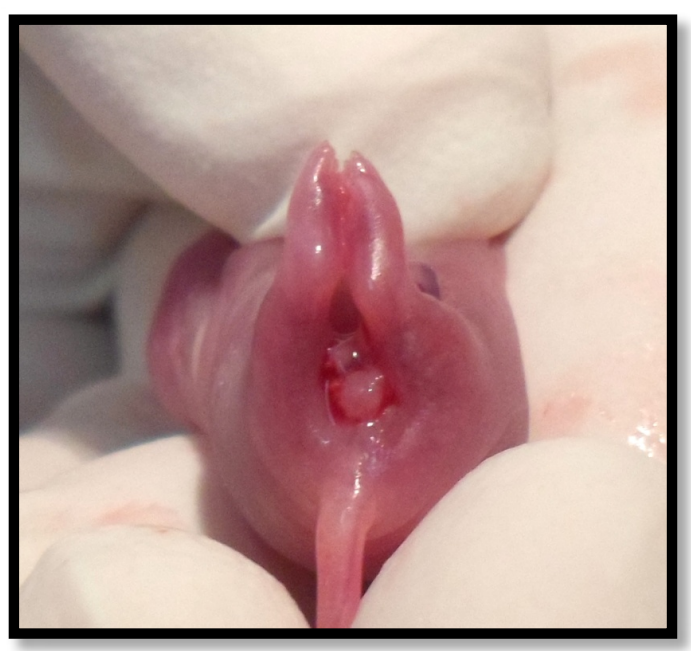

FIGURA 2 - ARM ETU induced.

\begin{tabular}{|c|c|c|c|}
\hline Group & $\mathrm{ASSE} \pm \mathrm{SD}(\boldsymbol{\mu m})$ & $\mathrm{IE} \pm \mathrm{SD}(\mu \mathrm{m})$ & $\operatorname{ARM}(\%)$ \\
\hline $\mathrm{AF}+\mathrm{ETU}$ & $28.88 \pm 0.56$ & $21.11 \pm 0.16$ & $2 \%$ \\
\hline ETU & $27.75 \pm 0.61$ & $18.88 \pm 0.93$ & $65 \%$ \\
\hline
\end{tabular}

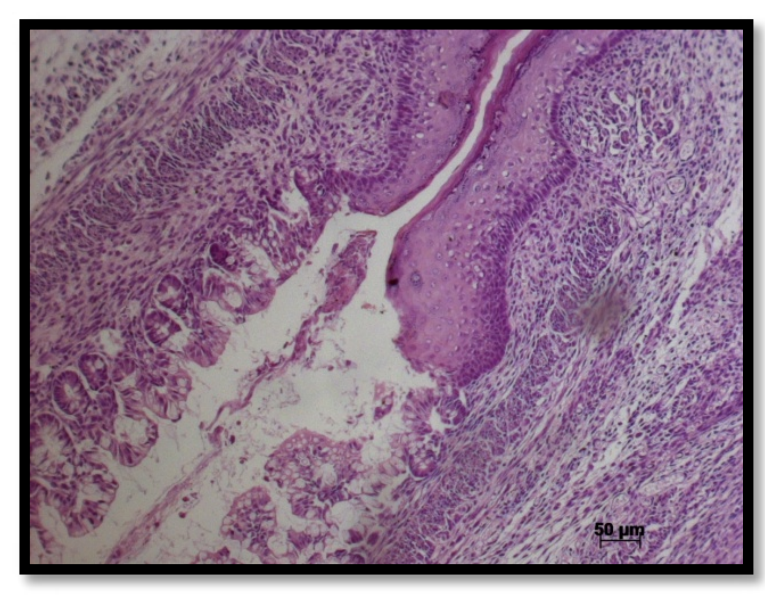

FIGURE 4 - Thickness of IE - No ARM - FA+ETU group (x20). 


\section{Discussion}

ARMs are among the most common congenital anomalies in humans. In male, rectourethral fistula has been the most common presentation, while vestibular fistula has been the most presented in females. The most of them present as an isolated malformation, although it may be part of VACTER anomalies. The term VACTER represents vertebral, anorectal, cardiovascular, tracheal, esophageal, renal and limb anomalies.

Currently, PSARP ${ }^{2}$ has been performed throughout the world. This technique allowed better understanding of anorectal anatomy. Despite optimal surgical management, many patients reclaim of bowel and voiding dysfunction. These dysfunctions occur probably because no adequate repair for poorly developed muscles or nerves has been developed at this time.

ARMs pathogenesis and morphogenesis remains unclear. Various experimental models have been published using different animals. Rats are the most common animal used, including mutant mice. Different teratogenic drugs have induced ARMs in rats. One of the most known and researched is ethylenethiourea (ETU).

Ethylenethiourea is one of degradation products of ethylenebisdithiocarbamate fungicides. ETU is also used as an accelerator for vulcanizing polychloroprene and polyacrylate rubbers. The routes of potential human exposure to ethylenethiourea are inhalation, ingestion, and dermal contact Individuals may be also exposed to ETU through consumption of food contaminated with fungicides ${ }^{5}$.

The first report of ARMs ETU-induced was in 1990. A single dose of ETU $(125 \mathrm{mg} / \mathrm{kg})$ by gavage on GD11 produces ARMs and central nervous system (CNS) defects. ARMs were induced $92 \%$ in males, whereas ARMs were induced $41 \%$ in females ${ }^{6}$.

From this moment, various papers have been published trying to explain the ARMs morphogenesis. The urorectal septum (URS), cloaca and cloacal membrane are relevant structures for anorectal embryogenesis. In these experimental models cloacal membrane is short. The URS is maldeveloped far away from the cloacal membrane, and the URS and cloacal membrane were never fused. The failure of fusion between URS and cloacal membrane was pointed as main cause of rectourinary fistula. There was no anal membrane rupture consequently rectum did not communicate outside ${ }^{7}$.

The previous work of our group has induced $71 \%$ of ARMs in rats treated by $\mathrm{ETU}^{8}$. In this paper, $65 \%$ of ARMs were induced by ETU. Our results are similar to other groups ${ }^{9-15}$.

Trying to figure out the enteric nervous system (ENS), the terminal intestine was analyzed by immunohistochemistry technique. Neuron-specific enolase (NSE), vasoactive intestinal peptide (VIP) and substance P 100 (PS100) were used to study the ENS and it was found neurons and ganglion cell densities in the myenteric plexus were decreased in ARMs ${ }^{16-18}$.

Interstitial cells of Cajal (ICC) are derived from the mesenchyme and expressing c-kit receptor on its surface. ICCs have an important role in controlling intestinal motility, acting as pacemakers in the gastrointestinal tract and as neurotransmission intermediaries in the ENS for smooth muscle cells. Thinner muscle layer associated with lower density of ganglion cells and ICC were observed in ARMs ETU-induced, suggesting severe nerve plexus abnormalities and muscular layer atrophy in this experimental model $^{18}$. Great number of ICC was found in detrusor muscle and in sub-epithelial layer of bladder ${ }^{19}$.

A defective sacral parasympathetic nucleus innervation to the rectum was related as a primary anomaly. This defect would be associated with ARMs during fetal development, contributing to poor postoperative anorectal function ${ }^{20}$. Postoperative anorectal function depends on many factors, such as pelvic floor muscles, innervation of pelvic floor muscles, and no spinal cord anomalies. Striated muscle complex (SMC) is one of the most important factors related to anorectal function. Various defects in SMC were described in ARMs, such as the increased distance between SMC and the perineal skin ${ }^{21}$.

Internal anal sphincter (IAS) is very important to continence. IAS is responsible for the normal rectal anal inhibitory reflex controlling the resting tonus in the anal canal and keeping the anus closed. These muscles are dysplastic in rats with $\mathrm{ARMs}^{10}$.

In this study, the thickness of EEPA and IE were thinner in ETU group. Folic acid did not modify significantly the thickness of EEPA $(p=0.2)$. On the other hand, the thickness of IE was significantly thicker in FA+ETU group than in ETU group. Fetuses with ARMs presented both thickness of EEPA and IE smaller than normal rats, but it was not possible to prove by statistical analysis. This analysis was only able to compare entire groups, but not each fetus individually.

Folic acid or folate is the generic term of a water soluble B vitamin. Folic acid has low toxicity. Folate refers to the deprotonated ion, while folic acid refers to the neutral molecule or the synthetic form of vitamin B. Folic Acid is more stable than folate.

Maternal FA deficiency was correlated with neural tube defects (NTD). FA provides well-documented benefit for the prevention of NTD and craniofacial defects. Currently, many countries recommend that all women planning or capable of pregnancy take a daily supplement containing $400-800 \mu \mathrm{g}$ of folic $\operatorname{acid}^{22-24}$. 
Few authors have studied the relationship between FA and ARMs, and their results are unclear. Some of them had not found any difference in development of ARMs when FA was taken ${ }^{25-27}$. On the other hand, other authors had related some protection of FA in development of ARMs ${ }^{4,28,29}$.

During folate metabolism, folate is converted by dihydrofolate reductase (DHFR) to tetrahydrofolate (THF), the naturally bioactive form. Methylenetetrahydrofolate reductase (MTHFR) catalyzes the conversion of THF to 5-methyltetrahydrofolate (5-MeTHF), the main form of folate in the blood circulation. Low enzyme activity of MTHFR reduces 5-MeTHF plasma levels, leading to increased levels of homocysteine. These changes have been related to neural tube defects. No relationship between ARMs and reduced enzyme activity of MTHFR was found ${ }^{27}$.

In this study, ARMs ETU-induced experimental model was easily replicated, with similar results to other studies. The mean weight of the fetuses was significantly higher when FA was administrated $(\mathrm{p}=0.025)$. FA reduces significantly the incidence of ARMs in this model from $65 \%$ to $2 \%(p<0.005)$. Further studies are necessary to explain how folic acid acts in this model.

\section{Conclusion}

Folic acid reduces the incidence of anorectal malformations induced by ethylenethiourea in rats.

\section{References}

1. Martins JL, Pinus J. Anomalías anorrectales: evaluación de resultados de su tratamiento quirúrgico en 162 niños tratados entre 1986 a 1999. Rev Cir Infant. 1999;9(4):221-6.

2. Peña A, Devries P. Posterior sagittal anorectoplasty: important technical considerations and new applications. J Pediatr Surg. 1982;17(6):796-811. doi: 10.1016/S0022-3468(82)80448-X.

3. Macedo M, Martins JL, Meyer KF, Soares IC. Study of density of interstitial cells of cajal in the terminal intestine of rats with anorectal malformation. Eur J Pediatr Surg. 2008 Apr;18(2):75-9. doi: 10.4103/1319-3767.105909.

4. Myers MF, Li S, Correa-villaseñor A, Li Z, Moore CA, Hong SX, Berry RJ. Folic acid supplementation and risk for imperforate anus in China. Am J Epidemiol. 2001;154(11):1051-6. doi: 10.1093/ aje/154.11.1051.

5. National Toxicology Program. Ethylenethiourea. Rep Carcinog. 2011;12:191-4. PMID: 21852838.

6. Hirai Y, Kuwabara N. Transplacentally induced anorectal malformations in rats. J Pediatr Surg. 1990;25(7):812-6. doi: 10.1016/S0022-3468(05)80028-4.

7. Bai Y, Chen H, Yuan ZW, Wang W. Normal and abnormal embryonic development of the anorectum in rats. $\mathrm{j}$ Pediatr Surg. 2004;39(4):587-90. doi: 10.1016/j.jpedsurg.2003.12.002.

8. Macedo M, Martins JL, Meyer KF. Evaluation of an experimental model for anorectal anomalies induced by ethylenethiourea. Acta Cir
Bras. 2007;22(2):130-6. doi: 10.1590/S0102-86502007000200010. 9. Dan Z, Bo ZZ, Tao Z, Wei ZS, Jia WD, Cheng ZS, Wei YZ, Wang WL. Hoxd-13 expression in the development of hindgut in ethylenethiourea-exposed fetal rats. J Pediatr Surg. 2010;45(4):75561. doi: 10.1016/j.jpedsurg.2009.11.011.

10. Zhang SW, Bai YZ, Zhang D, Zhang T, Zhang SC, Wang DJ, Wang WL. Embryonic development of the internal anal sphincter in rats with anorectal malformations. J Pediatr Surg. 2010;45(11):2195202. doi: 10.1016/j.jpedsurg.2010.06.020.

11. Jia H, Chen Q, Zhang T, Bai Y, Yuan Z, Wang W. Wnt5a expression in the hindgut of fetal rats with chemically induced anorectal malformations-studies in the ETU rat model. Int J Colorectal Dis. 2011;26(4):493-9. doi: 10.1007/s00384-010-1125-0.

12. Huang Y, Zheng S. The effect of vitamin A deficiency during pregnancy on anorectal malformations. J Pediatr Surg. 2011;46(7):1400-5. doi: 10.1016/j.jpedsurg.2011.02.042.

13. Huang Y, Zheng S. Effect of exogenous glial cell-derived neurotrophic factor on development of the enteric nervous system in the rectal end of fetal rats with anorectal malformations. Pediatr Surg Int. 2013;29(4):375-9. doi: 10.1007/s00383-012-3251-y.

14. Tang XB, Zhang J, Wang WL, Yuan ZW, Bai YZ. Spatiotemporal expression of $\mathrm{Cdx} 4$ in the developing anorectum of rat embryos with ethylenethiourea-induced anorectal malformations. Cells Tissues Organs. 2014;199(2-3):212-20. doi: 10.1159/000365965.

15. Tang XB, Zhang T, Wang WL, Yuan ZW, Bai YZ. Temporal and spatial expression of caudal-type homeobox gene-2 during hindgut development in rat embryos with ethylenethiourea-induced anorectal malformations. Cell Tissue Res. 2014;357(1):83-90. doi: 10.1007/ s00441-014-1858-0.

16. Mandhan P, Sullivan M, Quan QB, Beasley SW. The contribution of the sonic hedgehog cascade in the development of the enteric nervous system in fetal rats with anorectal malformations. J Pediatr Surg. 2007;42(12):2080-5. PMID: 18082712.

17. Macedo M, Martins JL, Meyer KF, Soares IC. Study of the density of ganglion cells in the terminal bowel of rats with anorectal malformations. Acta Cir Bras. 2007;22(6):441-5. PMID: 18235931.

18. Lemos SPP, Martins JL, Lemos PVRB, Silva SRG, Santos FL, Silva Jr VA. Abnormalities of digestive tract innervation in rat fetus treated with ethylenethiourea. Acta Cir Bras. 2012;27(3):244-50. PMID: 22460255.

19. Meyer KF, Martins JL, Macedo M, Freitas Filho LG, Wang L, Soares IC. Cajal cells in the bladder of rats with anorectal malformations. Einstein. 2007;5(3):258-63.

20. Jia H, Zhang K, Zhang S, Yuan Z, Bai Y, Wang W. Quantitative analysis of sacral parasympathetic nucleus innervating the rectum in rats with anorectal malformation. J Pediatr Surg. 2007;42(9):1544 8. PMID: 17848246.

21. Zhang SW, Bai YZ, Zhang SC, Wang DJ, Zhang T, Zhang D, Wang WL. Embryonic development of the striated muscle complex in rats with anorectal malformations. J Pediatr Surg. 2008;43(8):1452-8. doi: 10.1016/j.jpedsurg.2008.02.059.

22. Wolff T, Witkop CT, Miller T, Syed SB. Folic acid for the prevention of neural tube defects: U.S. Preventive Services Task Force recommendation statement. Ann Intern Med. 2009;150(9):626-31. doi: 10.7326/0003-4819-150-9-200905050-00009.

23. Wolff T, Witkop CT, Miller T, Syed SB. Folic acid for the prevention of neural tube defects: an update of the evidence for the U.S. Preventive Services Task Force. Ann Intern Med. 2009;150(9):6329. doi: 10.7326/0003-4819-150-9-200905050-00010.

24. Bower C, D'Antoine H, Stanley FJ. Neural tube defects in Australia: trends in encephaloceles and other neural tube defects before and after promotion of folic acid supplementation and voluntary food fortification. Birth Defects Res A Clin Mol Teratol. 2009;85(4):269 73. doi: 10.1002/bdra.20536. 
Faria DJF et al.

25. Källén B. Congenital malformations in infants whose mothers reported the use of folic acid in early pregnancy in Sweden. A prospective population study. Congenit Anom. 2007 ;47(4):119-24. PMID:17988253.

26. van Rooij IA, Wijers CH, Rieu PN, Hendriks HS, Brouwers MM, Knoers NV, de Blaauw I, Roeleveld N. Maternal and paternal risk factors for anorectal malformations: a Dutch case-control study. Birth Defects Res A Clin Mol Teratol. 2010;88(3):152-8. doi: 10.1002/bdra.20649.

27. Wijers CHW, de Blaauw I, Zwink N, Draaken M, van der Zanden LFM, Brunner HG, Brooks AS, Hofstra RM, Sloots CE, Broens PM, Wijnen MH, Ludwig M, Jenetzky E, Reutter H, Marcelis CL, Roeleveld N, van Rooij IA. No major role for periconceptional folic acid use and its interaction with the MTHFR C677T polymorphism in the etiology of congenital anorectal malformations. Birth Defects Res A Clin Mol Teratol. 2014;100(6):483-92. doi: 10.1002/ bdra.23256.

28. Czeizel AE, Tóth M, Rockenbauer M. Population-based case control study of folic acid supplementation during pregnancy. Teratology. 1996;53(6):345-51. PMID: 8910980.

29. Correa A, Gilboa SM, Botto LD, Moore CA, Hobbs CA, Cleves MA, Riehle-Colarusso TJ, Waller DK, Reece EA, National Birth Defects Prevention Study. Lack of periconceptional vitamins or supplements that contain folic acid and diabetes mellitusassociated birth defects. Am J Obstet Gynecol. 2012;206(3):218.e1-218.e13. doi: 10.1016/j.ajog.2011.12.018.

\section{Correspondence:}

José Luiz Martins

Rua dos Otonis, 131

04025-000 São Paulo - SP Brasil

Tel./Fax: (55 11)5575-4761

jlmartins1@terra.com.br

Received: Apr 20, 2015

Review: June 23, 2015

Accepted: July 242015

Conflict of interest: none

Financial source: none

${ }^{1}$ Research performed at Laboratory of Experimental Surgery, Universidade Federal de São Paulo (UNIFESP), Brazil. Part of Master degree thesis, Postgraduate Program in Interdisciplinary Surgical Science, UNIFESP. Tutor: José Luiz Martins. 